\title{
Efecto de diferentes crioprotectores sobre la motilidad espermática de la macha Mesodesma donacium (Mollusca, Bivalvia)
}

\author{
Roberto Joo y Enrique Dupré \\ Universidad Católica del Norte, Depto. Biología Marina, Casilla 117, Coquimbo, Chile \\ E-mail: edupre@ucn.cl
}

Recibido: 26 abril 2002; versión corregida: 12 septiembre 2002; aceptado: 2 octubre 2002

\begin{abstract}
RESUMEN. Se evaluó el efecto producido por diferentes crioprotectores en diferentes concentraciones y tiempos de incubación sobre la motilidad espermática post-tratamiento de espermatozoides de macha. Los crioprotectores utilizados fueron DMSO, metanol y propilén-glicol, en concentraciones de 0,5 M, 1,0 M y 1,5 M. y tiempos de incubación de 5, 10 y 15 min. Espermatozoides extraídos de la gónada y diluidos en agua de mar se mezclaron en proporción 1:1 con cada crioprotector. Después de cada incubación se evaluó la toxicidad producida por cada crioprotector mediante la evaluación de la motilidad espermática, diferenciándola en tres tipos (M1, M2 y M3). Se observó que los espermatozoides se activan sólo al tomar contacto con agua de mar, aumentando su movimiento flagelar hasta los 15 min y luego comienza a disminuir hasta los $95 \mathrm{~min}$. El mayor porcentaje de motilidad 3 (44,3\%) se obtuvo en espermatozoides incubados en DMSO $1 \mathrm{M}$ por $5 \mathrm{~min}$, lo cual sugiere que este crioprotector genera la menor toxicidad. Esto se debería al menor tamaño de las moléculas de los otros crioprotectores, las cuales pudieran estar atravesando las membranas plasmáticas con mayor facilidad provocando una más rápida y excesiva deshidratación de la célula, que provocaría un excesivo arrugamiento de la membrana y su rompimiento, lo cual no ocurre con el DMSO, o debido a que las moléculas de menor tamaño del propilén-glicol y metanol podrían afectar directamente las estructuras del flagelo.
\end{abstract}

Palabras claves: toxicidad, crioprotectores, criopreservación, espermatozoides, macha.

\section{Effect of different cryoprotectants on the sperm motility of the surf-clam Mesodesma donacium (Mollusca, Bivalvia)}

\begin{abstract}
Toxicity of DMSO, methanol and prophylene glycol at $0.5 \mathrm{M}, 1.0 \mathrm{M}$ and $1.5 \mathrm{M}$ at 5, 10 and 15 min of incubation time are analyzed. The spermatozoa removed from the gonad where diluted in $5^{\circ} \mathrm{C}$ seawater and later mixed in proportion 1:1 with the corresponding cryoprotectants. The toxicity generated by the cryoprotectants, after the incubation were evaluated by sperm motility. Three type of motility were differentiated (M1, M2 y M3). The fresh spermatozoa were activated at contact with seawater increasing flagellar movement until 15 min and them diminished until to $95 \mathrm{~min}$. After the incubation of the sperm in each one cryoprotectant, the highest recovery of forward motility (type 3) was $44.3 \%$ at DMSO 1.0 M incubated during $5 \mathrm{~min}$, which suggest that DMSO produce the low toxicity. Though the molecules of the other cryoprotectant are smaller and could easier penetrate into de cell, they can cause a faster dehydration and thereby destruction of the membranes by shrinking or could be affecting directly the flagellar structures.
\end{abstract}

Key words: toxicity, cryoprotectant, cryopreservation, spermatozoa, surf- clam.

En Chile, los estudios sobre criopreservación son escasos y se refieren a larvas de erizos (Barros et al., 1996), espermatozoides de truchas (Conget et al., 1996) y de bivalvos (Dupré y Espinoza, 2000). Entre los bivalvos chilenos de importancia comer- cial, además de ostras y ostiones, está la macha Mesodesma donacium (Lamarck, 1818), cuyo futuro está siendo amenazado por la sobrexplotación ejercida en los últimos 10 años (SERNAPESCA, 2001). Recientemente, Miranda (2001) informó la 
desaparición total del banco de machas que existía en la bahía de Coquimbo, atribuyéndolo a la sobreexplotación sumada al fenómeno de El Niño. Esta situación ha generado políticas de resguardo como el establecimiento de áreas de manejo o la generación de programas de mejoramiento genético. En este aspecto, la criopreservación adquiere gran relevancia permitiendo la creación de bancos espermáticos para preservar las características genéticas de importancia para los cultivadores.

La criopreservación está basada en la congelación de células, grupos celulares u organismos completos en nitrógeno líquido por largos períodos de tiempo, conservando su viabilidad. Este proceso es ayudado por la aplicación de soluciones químicas que protegen con alta efectividad a las células del daño producido por la formación de cristales de hielo durante el proceso de congelación y descongelación. La eficiencia de estas soluciones crioprotectoras depende de la permeabilidad de la membrana plasmática y de la toxicidad que produce al penetrar a la célula tratada. Esto significa que cada grupo celular u órgano responde de distinta manera a los crioprotectores, lo que se traduce en que las diferentes especies requieran de distintos crioprotectores, diferentes concentraciones de cada crioprotector y diferentes tiempos de permanencia en la solución crioprotectora (Rana, 1995). Así, cada especie responde de distinta manera a estos crioprotectores, originando diferentes efectos sobre los organismos al aplicar las mismas metodologías (Renard y Cochard, 1989), lo cual indica que los crioprotectores son especie-específicos (Yao et al., 2000).

En el presente estudio se determina el efecto producido por tres crioprotectores, sobre la motilidad post-tratamiento que presentan los espermatozoides de Mesodesma donacium, proporcionados en diferentes concentraciones y tiempos de incubación, como primera etapa para su criopreservación.

Los espermatozoides se extrajeron por disección desde machos maduros de $M$. donacium colectados en las bahías de Tongoy y Coquimbo, y se mantuvieron a $5^{\circ} \mathrm{C}$ al igual que las soluciones crioprotectoras. Se formó una solución madre agregando $20 \mathrm{~mL}$ de espermatozoides concentrados en $50 \mathrm{~mL}$ de agua de mar microfiltrada a $20 \mathrm{~mm}$ (AMF). En una cápsula Petri se mezcló $1 \mathrm{~mL}$ de AMF y 1 $\mathrm{mL}$ de una de las soluciones crioprotectoras, al doble de la concentración final, a la cual se agregó 1 $\mathrm{mL}$ de espermatozoides de la solución madre. Los crioprotectores utilizados fueron dimetilsulfóxido (DMSO), metanol y propilén-glicol en concentraciones de 0,5 M, 1,0 M y 1,5 M. Después de incubar los espermatozoides en estas soluciones a temperatura ambiente $\left(16-17^{\circ} \mathrm{C}\right)$ por 5,10 y $15 \mathrm{~min}$ (tiempo de equilibrio), se diluyeron en $50 \mathrm{~mL}$ de AMF y se determinó la concentración espermática $\left(3,75 \times 10^{6}\right.$ y $\left.5 \times 10^{6} \mathrm{esp} / \mathrm{mL}\right)$ y su motilidad con un hematocitómetro, con microscopio de 200 aumentos. Las motilidades (M) en los espermatozoides se clasificaron como: M1 sin movimiento; M2 con movimiento flagelar lento y zigzagueante, y M3 con movimiento de flagelo rápido y desplazamiento efectivo.

Se observó que los espermatozoides recientemente extraídos del testículo, se activaron sólo al tomar contacto con agua de mar. Al inicio, el movimiento del flagelo es lento, ondular y sin desplazamiento; a medida que transcurre el tiempo, los espermatozoides comienzan a desplazarse hasta llegar a un movimiento rápido de trayectoria circular compleja, difícil de describir. El porcentaje de espermatozoides móviles aumentó hasta $88,5 \%$ entre 0 y 15 min (Fig. 1) y luego disminuyó lentamente hasta alcanzar 55,7\% a los 95 min (Fig. 1), sugiriendo que no todos los espermatozoides se activan al mismo tiempo.

Se determinaron diferencias significativas $(\mathrm{p}<0,001)$ entre las motilidades espermáticas tipo M3 (con desplazamiento efectivo) después de ser incubados en los diferentes crioprotectores, no así entre las diferentes concentraciones y tiempos de incubación en cada crioprotector. Las diferencias se produjeron entre DMSO y metanol, y entre DMSO y propilén-glicol; en cambio no se encontraron diferencias entre propilén-glicol y metanol (Fig. 2). Los mejores porcentajes de motilidad M3 (44,3\%) se obtuvieron en DMSO a una concentración $1 \mathrm{M}$ con 5 min de incubación (Fig. 3).

Aún cuando no se determinaron diferencias significativas entre las motilidades de espermatozoides incubados en metanol (Fig. 4a) y propilén-glicol (Fig. 4b), es evidente que las motilidades fueron menores al incubarlos en propilén-glicol.

Estos resultados muestran que el crioprotector que produjo menor daño en los espermatozoides fue el DMSO y se debería a que este producto posee moléculas de mayor tamaño que el metanol y propilén-glicol, las cuales podrían estar atravesando las membranas con menor velocidad que los otros, causando una deshidratación menor en los 


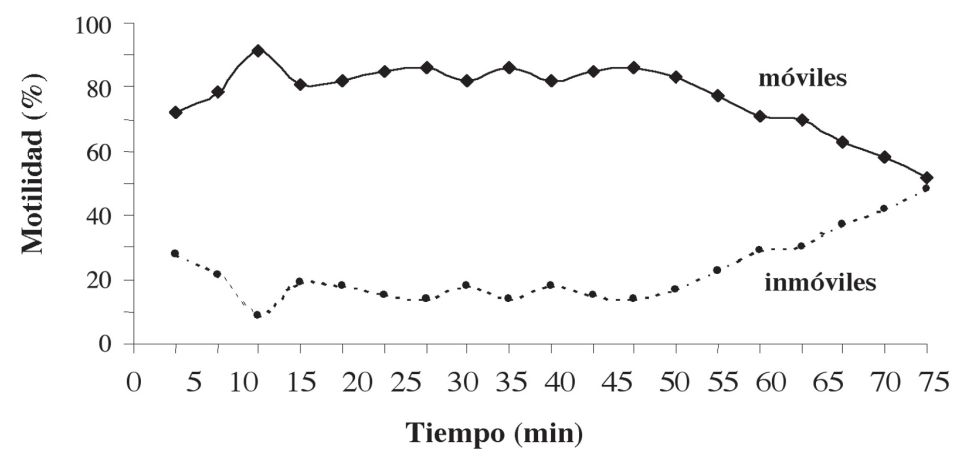

Figura 1. Variación de la motilidad total de espermatozoides frescos extraídos del testículo de Mesodesma donacium y diluidos en agua de mar.

Figure 1. Motility of fresh spermatozoa extruded from the testicle of Mesodesma donacium and diluted in seawater.

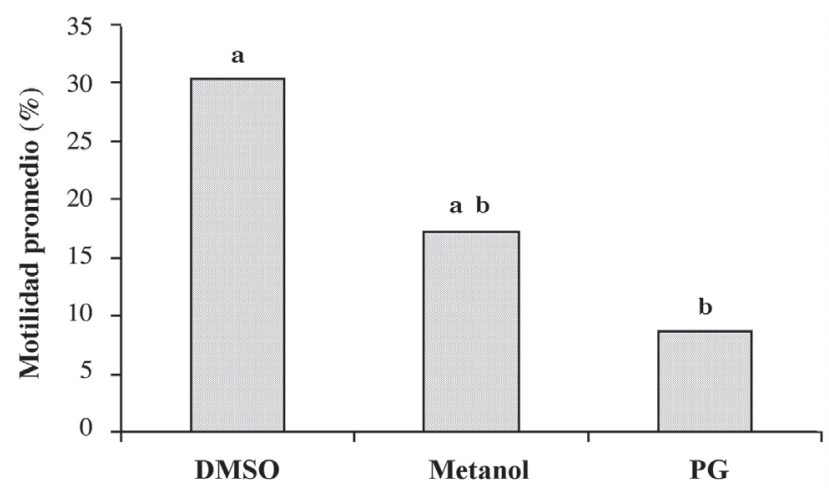

Figura 2. Motilidad espermática promedio tipo M3 después de ser tratados con diferentes crioprotectores, considerando las tres concentraciones $(0,5 \mathrm{M}, 1,0 \mathrm{M}, 1,5 \mathrm{M})$ y los tres tiempos de exposición al crioprotector (5, 10 y 15 min). DMSO, dimetilsulfóxido; PG, propilén-glicol; a y b, difieren significativamente.

Figure 2. Sperm motility average type 3 after treatment with different cryoprotectant, considering the three concentration $(0.5 \mathrm{M}, 1.0 \mathrm{M}, 1.5 \mathrm{M})$ and the three incubation time in the cryoprotectant $(5,10$ and $15 \mathrm{~min})$. DMSO, dimethylsulfoxide; PG, prophylen-glycol; a, b, significant differences.

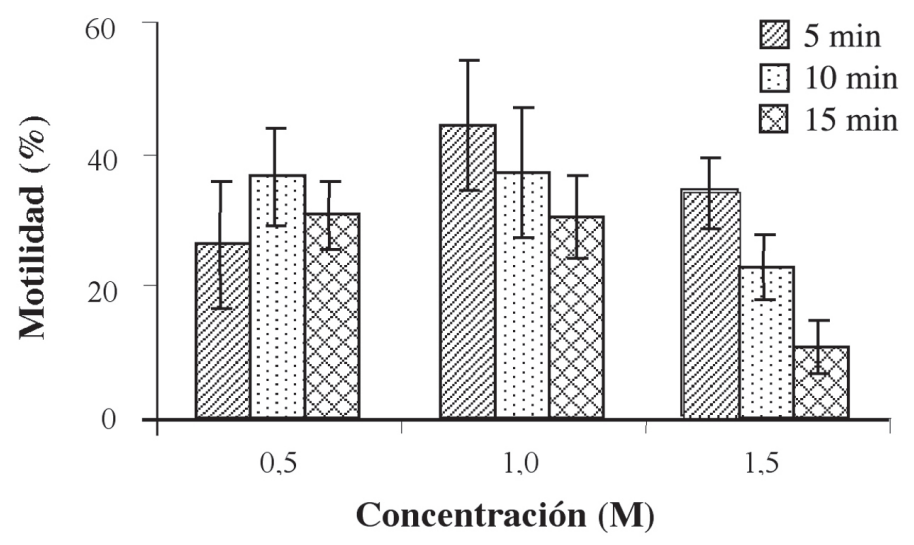

Figura 3. Motilidad espermática tipo 3 obtenida después de incubarlos en diferentes concentraciones de dimetilsulfóxido (DMSO) y tiempos de incubación.

Figure 3. Sperm motility type 3 obtained after different concentration of DMSO and different incubation time. 

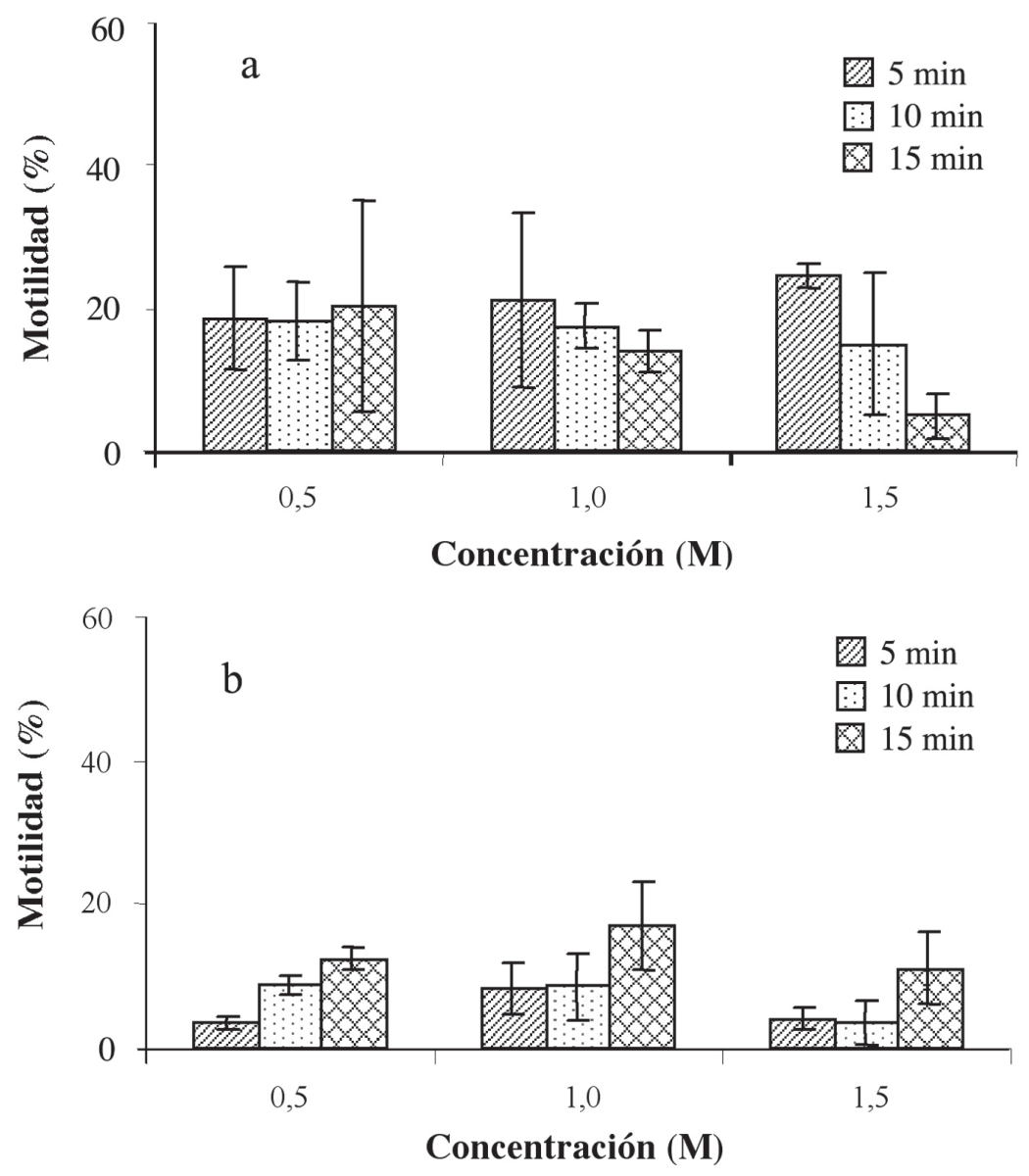

Figura 4. Motilidad espermática tipo 3 obtenida después de incubarlos a diferentes concentraciones y tiempos de exposición en a) metanol y b) propilén-glicol.

Figure 4. Sperm motility type 3 obtained after different concentration and different incubation time in a) methanol and b) prophylene-glycol.

mismos tiempos de incubación que metanol y propilén-glicol, evitando así una deshidratación brusca como ocurriría con los otros crioprotectores utilizados, originando el rompimiento de las membranas por arrugamiento de ella (Meryman, 1971). Otra posibilidad es que las moléculas de menor tamaño podrían afectar directamente las estructuras flagelares.

\section{AGRADECIMIENTOS}

Este estudio fue financiado por la Dirección de Investigación Científica y Tecnológica de la Universidad Católica del Norte (DGICT-UCN).

\section{REFERENCIAS}

Barros, C., A. Muller, M.J. Wood y D. Whittingham. 1996. High survival of sea urchin semen (Tetrapigus niger) and pluteus larvae (Loxechinus albus) frozen in 1.0 $\mathrm{M} \mathrm{Me}_{2} \mathrm{SO}$. Cryobiology, 33(6): 646-651.

Conget, P., M. Fernández, G. Herrera y J. Minguell. 1996. Cryopreservation of rainbow trout (Oncorhynchus mykiss) spermatozoa using programmable freezing. Aquaculture, 143: 319329. 
Dupré, E. y C. Espinoza. 2000. Determinación de porcentajes de fecundación del ostión del norte Argopecten purpuratus utilizando espermatozoides criopreservados. Informe final, Proyecto DGIUCN. Universidad Católica del Norte, Coquimbo, $29 \mathrm{pp}$.

Meryman, H. 1971. Cryoprotective agents. Cryobiology, 8(2):173-183.

Miranda, C. 2001. La desaparición del banco de machas Mesodesma donacium (Lamarck, 1818) (Mollusca: Bivalvia; Mesodesmatidae) en la bahía de Coquimbo IV Región, Chile: sus probables causas. Tesis de Biología Marina, Universidad Católica del Norte, 50 pp.

Rana, K. 1995. Preservation of gametes. En: N. Bromage y R. Roberts (eds.). Broodstock management of egg and larval quality. Blackwell Scientific Publications, Oxford, pp. 53-73.
Renard, P. y J. Cochard. 1989. Effects of various cryoprotectants on Pacific oyster Crassostrea gigas Thumberg, Manila clam Ruditapes philippinarum Reeve and king scallop Pecten maximus (L) embryos. Influence of the biochemical and effects. Cryo-Letters, 10: 169-180.

Servicio Nacional de Pesca (SERNAPESCA). 2001. Anuario estadístico de pesca. Servicio Nacional de Pesca. Ministerio de Economía, Fomento y Reconstrucción, $291 \mathrm{pp}$.

Yao, Z., L. Crim, G. Richardson y C. Emerson. 2000. Motility, fertility and ultrastructural changes of ocean pout (Macrozoarces americanus L.) sperm after cryopreservation. Aquaculture, 81: 361-375. 